\title{
Starting well, ending better!
}

\author{
Dr Hanif Moti of Moti Smile Design Centre, Leicester, \\ describes why oral health promoters are good news \\ in his Starting Well practice.
}

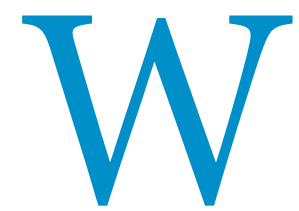

e have always been a practice that has been led on the principle of prevention. We are a large team of 18 , including six dentists, a dental hygienist, two oral health promoters and nine dental nurses. Based in Leicester, we are a BDA Good Practice and have worked hard to build a trusted local reputation. We have also been an Investors in People accredited practice since 2000 .

We were keen and early adopters of the BSPD's Dental Check by One scheme that aims to see all children in the dental practice before the age of two. We have a dental hygienist and an oral health educator and the team meet regularly to discuss how we can better improve all our patients' oral health. In 2016 we were awarded the Healthy Teeth, Happy Smiles award at an event opened by Rory Palmer, the Deputy City Mayor and Chair of Leicester Health. The event was also attended by the Deputy Chief Dental Officer Janet Clarke. The scheme aims to provide free toothbrushes and toothpaste, free baby

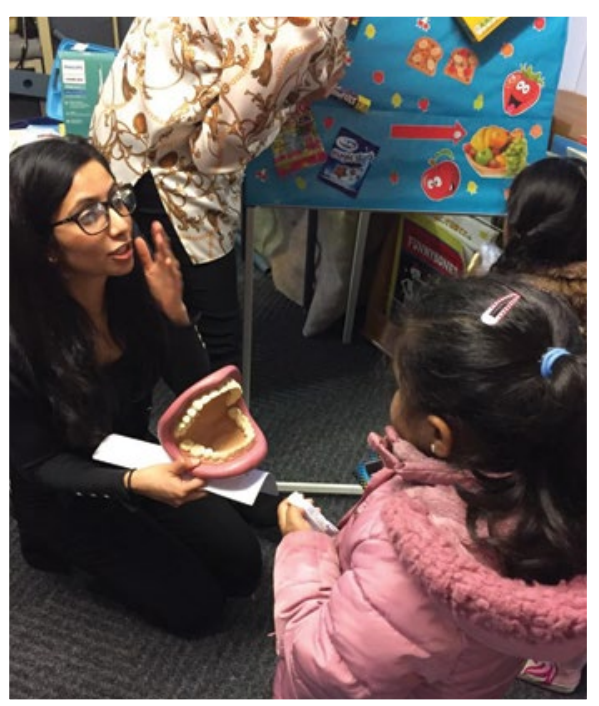

bottle swaps, and supervised tooth brushing. The accreditation programme was set up by Leicester City Council and promoted by Public Health Leicester. They organised events in the community such as supervised brushing workshops.

However, we're not smug. Leicester is one of 13 high priority areas chosen on the basis of decay experience at a local authority level. Sara Hurley came to Leicester to speak about the scheme and I attended alongside my oral health educator, Saadya Zarin. We felt that it fitted in with our approach and were keen to sign up.

In summer 2017 we joined the scheme and we found a local school and began working with them on three planned sessions across the three terms:

- Autumn - Under 5s tooth brushing and oral hygiene

- Spring - Dietary advice

- Summer-Oral hygiene.

It was paramount that the parents attended the tooth brushing session. Only by having them present could we hope for any lessons learned by the children to be reinforced and repeated. It could be argued that the session was perhaps more important for the parents than the children!

Starting Well is our attempt to reach out to the $50 \%$ of the UK population who don't attend the dentist. We have also teamed up with local GPs and pharmacists and leave literature and fliers with them to pass on to patients. This has led to significant numbers of patients coming to us from these sources.

We feel that being a part of the Starting Well scheme has further enhanced our already prevention based approach. The whole team is involved - not just the clinicians. The whole team has had training on what and how to deliver the right message. We try wherever possible to encourage families to visit as a

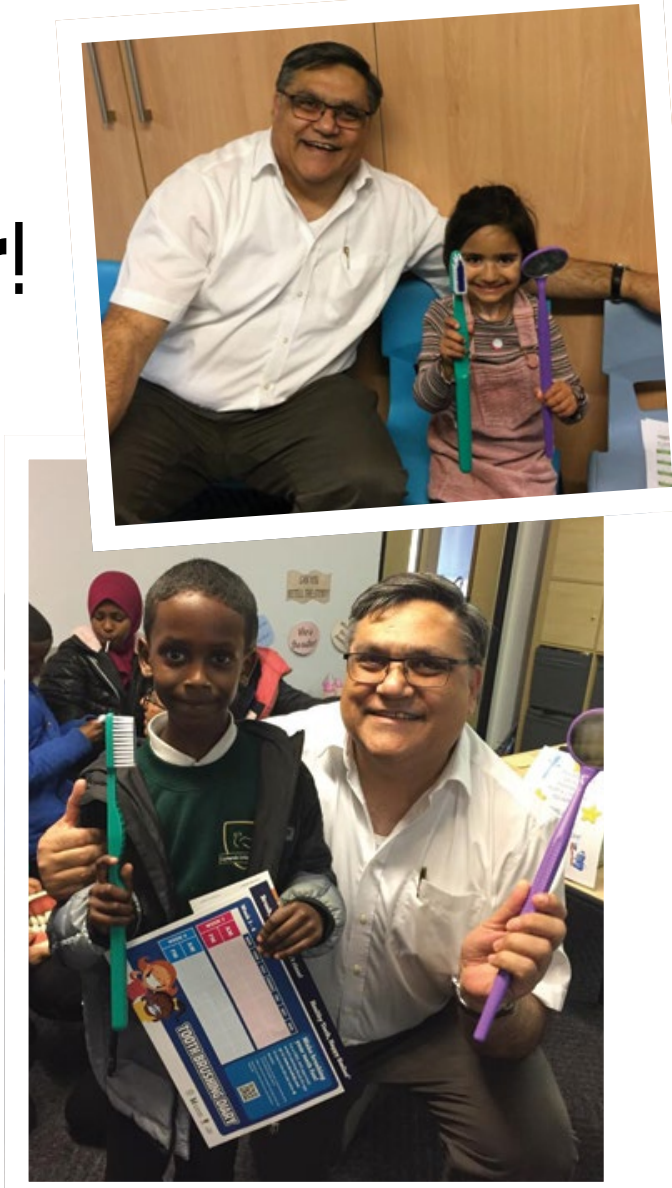

group. This allows us to reinforce the key messages of attendance and prevention.

If we have patients who are pregnant, we begin the educational journey as early in the pregnancy as possible. If parents are educated, it becomes second nature to bring their children in before the age of one. We have a staff meeting every week to review how we are doing against these targets and we make plans for the coming week.

Starting Well and its preventative approach is now second nature to us and we have seen a marked increase in younger and younger children attending the practice. We have fully got behind the campaign and want to see it grow further. We carry out regular audits in terms of patient numbers, changes that we are seeing so that we can illustrate that we are delivering a social return on investment. It's still quite early days but certainly the initial signs are positive. As time moves forward, we will hope to see:

- As many members of our team as possible to qualify as oral health educators. As a practice, we will support this in terms of time and financially too

- As many children/young families as we can!

www.motismiledesign.co.uk

DOI: 10.1038/s41407-019-0105-7 